\title{
Stormwater Management by Green Roof
}

\section{Suvada Jusić*, Emina Hadžić and Hata Milišić}

Faculty of Civil Engineering, Department of Water Resources and Environmental Engineering, University of Sarajevo, Sarajevo, Bosnia and Herzegovina

*Corresponding Author: Suvada Jusić, Faculty of Civil Engineering, Department of Water Resources and Environmental Engineering, University of Sarajevo, Sarajevo, Bosnia and Herzegovina.

Received: May 23, 2019; Published: June 06, 2019

DOI: $10.31080 /$ ASAG.2019.03.0516

\section{Abstract}

Urban impermeable areas such as roads, buildings and roofs produce a significant stormwater runoff. Under the big storm events, also caused by climate change especially, stormwater runoff may cause flooding, landslides and other water-related problems. Conventional drainage system doesn't have enough design capacity for reception all increased runoff. Green roofs perform very well as a stormwater management tool by providing reducing stormwater runoff generation. Additional benefits provided by green roofs (improved stormwater quality, improved aesthetics and environmental preservation etc.) makes this tool a desirable option for sustainable stormwater quality and quantity management. The main purpose of this paper is to present the design of green roofs and its roles and benefits in urban stormwater management. There are also presented experience in application and efficiency of green roof in different circumstances by reviewed some researches.

Keywords: Green Roof; Stormwater Runoff; Stormwater Management; Drainage System

\section{Introduction}

Cities have paved over natural green spaces to make way for streets, homes, and commercial developments. Urban stormwater can be defined as the extreme runoff from pervious and impervious surfaces that include roofs, driveways, pavements, footpaths, and roads infrastructure characteristic of urban areas [1,2]. In the developed urban areas, roof surface areas account for $40-50 \%$ of all total impervious surface areas. Also, climate change has caused more frequent and intense storms. The effects of global warming because of climate change is already increasing vulnerability of several urban areas around the world, through raising sea levels, inland floods, more frequent droughts, periods of increased heat, and the spread of diseases [3]. Due to climate change and urbanization stormwater runoff rates, volumes and pollution are getting more and more increased. Technologies of stormwater management (SWM) systems need to be improved to account for the changes in the hydrologic cycle that results from urbanization and changes of runoff caused by climate changes $[4,5]$.
Approaches to stormwater management known as 'Sustainable (Urban) Drainage systems' (SUDS), 'Low Impact Development' (LID), or 'Best Management Practices' (BMPs), represent a diverse range of control procedures, which integrate stormwater quality and quantity control as well as enabling social and amenity perspectives to be incorporated into stormwater management approaches [6,7]. For example, the aim of LIDs include: treating stormwater as close to the source as possible, decreasing impervious area, and implementing systems that have multiple functions (i.e. attenuating peak flow rates, storage of precipitation, delay of stormwater generation, infiltration, filtration, enhancing aesthetics, improve ecology) [8-10]. The implementation of a stormwater control as a retrofit on vacant roofs could significantly reduce the impervious surface cover and help decrease stormwater runoff and pollution generation at the source.

\section{Green roof design}

The goals of stormwater system design, is typically to preserve groundwater, prevent geomorphic changes in waterways, prevent 
flooding risks, protect water quality, and maintain aquatic life $[11,12]$. New SWM techniques are designed to maximize stormwater runoff reduction and provide flow rate control. A green roof system is a vegetative layer grown as an extension of an existing roof. It is built on new and existing roof structures which need to be prepared to fit this special purpose.

For example, it needs to have a good waterproofing and root repellent system; it needs to include a drainage layer and a filter cloth, a mulch layer and lightweight growing medium and plants (Figure 1).

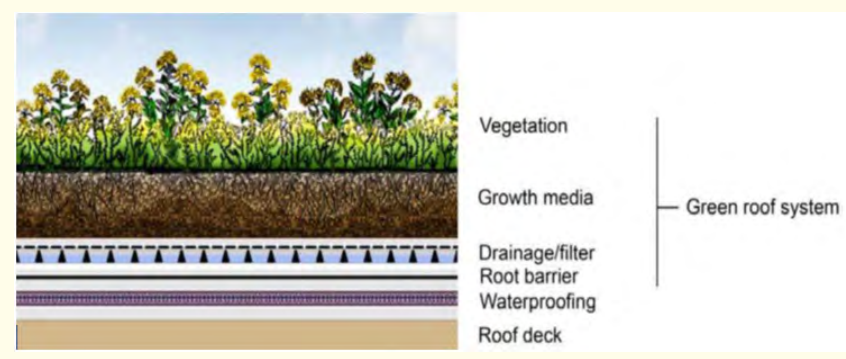

Figure 1: Typical green roof cross section [11].

Typically, a green roof design consists of three layers: vegetation, substrate (growth media) and drainage [11,12]. Each layer of the conventional green roof system (Figure 1) has an important function.

- Vegetation Layer: The vegetation will reduce wind erosion, provide shading for the substrate, and reduce the temperature during daylight hours in the warm season. Transpiration restores water storage capacity to the media, and the canopy can provide interception storage. Plant selection in most cases should be restricted to native varieties of grasses.

- Growing Media (substrate): An engineered substrate generally consisting of sand, gravel, crushed rock and some organics. The substrates main purpose is to store excess rainfall and support plant life. Standard soils are not used because they are too heavy for roof structures and a calculated ratio of aggregate, organic materials, air and water is used.

- Drainage Layer: A synthetic mat or a layer of porous media that permits conveyance of excess precipitation to outlets and roof drains. Water Proofing Membrane: The first layer directly above the conventional surface. Insulation should be placed above or below the water proofing membrane, as well as a root barrier to stop root invasion.
The green roof can be classified depending on the depth of the substrate layer and can be named as extensive roofs and intensive roofs $[13,14]$. Table 1 summarizes the attributes of the extensive and intensive green roofs.

\begin{tabular}{|c|c|}
\hline Extensive green roof & Intensive green roof \\
\hline Shallow growing medium & $\begin{array}{c}\text { Deeper growing medium } \\
(>150 \mathrm{~mm})\end{array}$ \\
\hline $\begin{array}{l}\text { Lightweight structure to } \\
\text { support roof }\end{array}$ & $\begin{array}{l}\text { Heavier roof structure } \\
\text { required }\end{array}$ \\
\hline $\begin{array}{l}\text { Cover large expanses of } \\
\text { rooftop }\end{array}$ & Small trees and shrubs feature \\
\hline $\begin{array}{l}\text { Requires minimum } \\
\text { maintenance }\end{array}$ & More maintenance required \\
\hline Lower capital cost & More expensive \\
\hline Not usually recreational & $\begin{array}{l}\text { More common in tropical } \\
\text { climates }\end{array}$ \\
\hline $\begin{array}{l}\text { Does not usually require } \\
\text { irrigation } \\
\text { Minimum structural } \\
\text { implications for existing } \\
\text { buildings }\end{array}$ & \\
\hline
\end{tabular}

Table 1: Attributes of extensive and intensive green roofs [11].

Site conditions such as annual precipitation, sun exposure, periods of drought, frost or snow and building structure (additional load, slope of roof, wind), in addition to owner preferences, are used to determine whether an intensive or extensive roof should be installed.

Using an appropriate design which integrates different technical options can prove useful to increase the efficiency of green roofs in different regions and under different climatic conditions [12]. The 'Guidelines for the Planning, Construction and Maintenance of Green Roofing' contain relevant regulatory information on the construction and maintenance of different types of green roof systems.

\section{Stormwater management by green roof}

The effectiveness of green roof's as a stormwater management approach (LID control) depends mainly on its ability to retain runoff, attenuate peak flow rates, while providing energy, ecological and other benefits [15]. Three factors have a major influence on the hydraulic as well as pollutant removal performance/benefits of green roofs: i. precipitation (duration, intensity); ii. substrate layers (type, thicknesses); and iii. the types of vegetation used in the green roofs $[11,12]$. 


\section{Rainfall runoff management}

The main potential of green roof is noted in the rainfall runoff management. Green roofs provide an opportunity to retain the stormwater for a longer period of time in urban areas. At first, the rainwater is stored in soil media and then to the vegetation layer of the green roof, which normally helps to reduce the peak flow and volume as compared to the conventional roofs as manifested in Figure 2 [3]. Figure 2 shows the runoff peak and volume delay by using green roof in an urban area. The green roof is an effective approach to decrease runoff and to increase the time of concentration as compared to a conventional roof in urban areas. In addition, it can also help to reduce the total runoff volume reduction in the urban drainage system. During the analysis, it was also found that green roofs could reduce $56 \%$ of runoff as compared to the conventional roofs. Green roof vegetation also allows evapotranspiration (EV) [3], which can also help to reduce the runoff volumes as compared to the conventional roofs where evapotranspiration (EV) is almost zero.

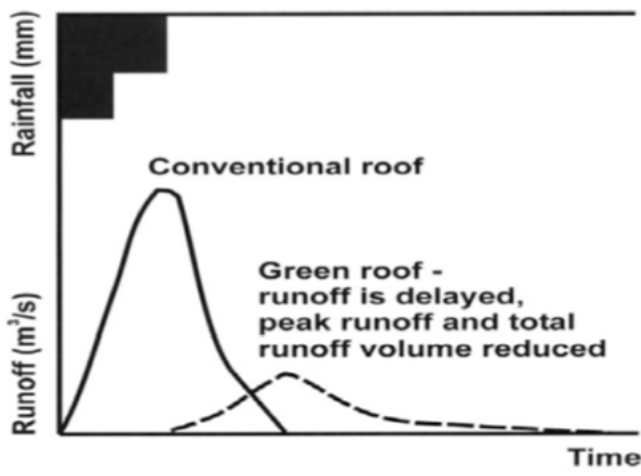

Figure 2: Rainfall runoff response of the green roof and conventional roof [3].

\section{Pollution control}

Historically, roof runoff has been regarded as a source of clean water for drinking, irrigation, and other domestic uses [12,15]. However, recent studies have examined water quality in roof catchments constructed for domestic water supplies in Northern Europe and in developing countries. Elevated zinc levels in roof runoff after the first flush, indicating that zinc was leaching from the galvanized roof surface during the storm. Although sample concentrations did not indicate an immediate threat to human health, zinc concentrations that are not a concern in drinking water may be toxic to aquatic life.
It has been found that green roofs may improve runoff water quality $[16,17]$. Green roofs may neutralize the acidity of rainfall. Additionally, runoff from an extensive green roof can reduce lead by $99 \%$, Zinc by $96 \%$, Cadmium by $92 \%$, and copper by $97 \%$. This reduction in heavy metals is largely a result of total pollutant load reduction due to retention rather than an effective filtration process. The nutrient concentration in the effluent will depend on fertilization methods.

\section{Other green roof benefits}

The main benefit of green roof is stormwater management, mentioned and explained in previous chapter. Also, there are additional benefits of green roofs which are briefly explained in this chapter [12,17]. Although the initial investment cost of the green roof technology is higher than standard roofing, the costs can be recovered by these different benefits/advantages.

\section{Reduce energy consumption}

Green roofs can provide energy savings, especially in poorly insulated buildings. In warm climates, the green roof will cool the building by shading the roof, preventing direct solar radiation and adding extra insulation. The green roof also stabilizes daily temperature fluctuations. Green roof vegetation uses about $60 \%$ the incoming solar radiation for photosynthesis.

\section{Reduce air pollution}

Green roofs act to replace vegetation removed due to urbanization. Green roofs have the potential to remove $\mathrm{NOx}, \mathrm{SO}_{2}$ and particulate matter. Additionally, the air pollution from manufacturing of materials for the green roof is offset within 13 years of green roof operation.

\section{Increase roof life}

Green roof can increase the life of a 10-20 year water proofing layer to 50 years.

\section{Reduce acoustics and noise}

Vegetation and soil can reduce noise in urban settings. The media depth directly relates to noise reduction; as the depth is increased, improved noise reduction is experienced.

\section{Ecological preservation}

Green roofs can augment fruit and vegetable production as well as provide habitats for small creatures and insects. Species including bees, caterpillars, grasshoppers, spiders, and beetles have been seen on London, on green roofs. 
Moreover, green roofs visually enhance the quality of life in cities.

Application of green roof

Over the last 30 years, green roofs have become more popular, particularly in most of the developed countries such as: Germany, Australia, Switzerland, Austria, USA, Japan, Kina, Singapore and South Korea [19]. For example, a law in Tokyo requires the installation of green roofs in private buildings with built areas larger than $1000 \mathrm{~m} 2$ and in public buildings with built areas larger than 250 $\mathrm{m} 2$, while integrated green roofs must encompass not less than $20 \%$ of the whole roof-top area.

By source of European Federation of Green Roofs and Walls (EFB) there are currently 14 European national green roof and wall associations that are members of Federation (Austria VfB), Belgium (BVGG), Czech Republic (SZUZ), Germany (FBB), Greece (GRGR), France (ADIVET), Hungary (ZEO SZ), Italy (AIVE P), Netherlands (VBB), Poland (PSDZ), Portugal (ANCV), United Kingdom (livingroofs.org), Scandinavia: Sweden, Norway, Denmark, Finland (SGRA) and Switzerland (SFG) [20]. Currently there are 86 million $\mathrm{m} 2$ of green roofs that have been installed in Germany and many flat roofs are already greened (Table 2). In most countries the majority of green roofs are extensive with the exception of Hungary. Here the market is mainly in the area of intensive green roofs (65 $\%$ ). There is great potential to increase the market for green roofs and walls throughout Europe (Table 2).

\begin{tabular}{|l|c|c|c|c|}
\hline \multicolumn{1}{|c|}{ Country } & $\begin{array}{c}\text { Green Roof } \\
\text { Stock } \\
\text { total } \mathbf{~ m}^{\mathbf{2}} \\
\mathbf{( 2 0 1 4 )}\end{array}$ & $\begin{array}{c}\text { Green } \\
\text { Roofs new/ } \\
\text { year }^{\text {m} 2}\end{array}$ & $\begin{array}{c}\text { ratio } \\
\text { exten- } \\
\text { sive \% }\end{array}$ & $\begin{array}{c}\text { ratio } \\
\text { inten- } \\
\text { sive \% }\end{array}$ \\
\hline Austria & 4.500 .000 & 500.000 & 73 & 27 \\
Germany & 86.000 .000 & 8.000 .000 & 85 & 15 \\
Hungary & 1.250 .000 & 100.000 & 35 & 65 \\
Scandinavia & & 600.000 & 85 & 15 \\
Switzerland & & 1.800 .000 & 95 & 5 \\
UK & 3.700 .000 & 250.000 & 80 & 20 \\
TOTAL: & 95.450 .000 & 11.250 .000 & & \\
\hline
\end{tabular}

Table 2: Data about Green Roofs in Europe [20].

Germany is well known for its modern-day green roofs, with a green roof industry growing 10 to $15 \%$ annually [20,21]. Here, an estimated $14 \%$ of all flat-roofed buildings are covered with green roofs (Figure 3). As an example of how countries make progress with green roof technology, the city of Hamburg plans from 2015 onwards to cover at least $70 \%$ of newly constructed flat or lowpitched roofs with green roof according to the city's new green roof strategy.

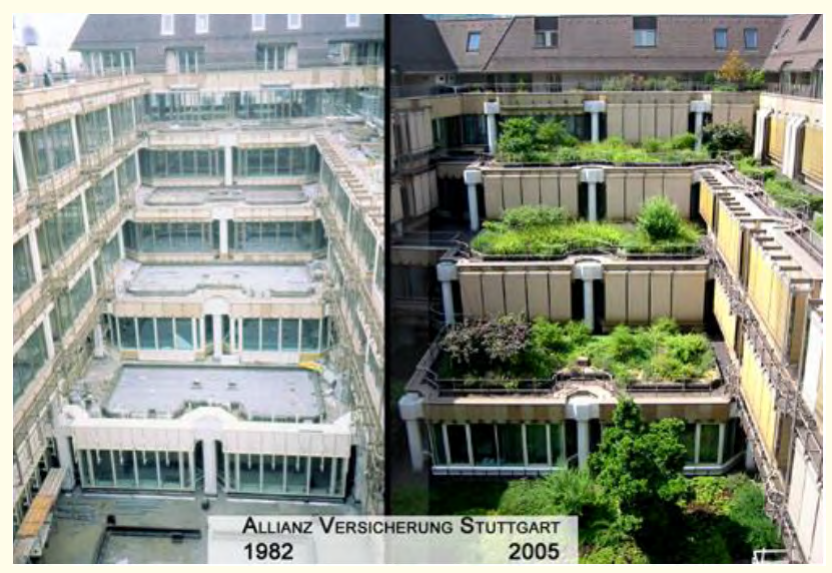

Figure 3: German company before and after green roof installation photo [5].

Green roof modeling and efficiency in different circumstance

In view of the runoff generation characteristics of green roof, mathematical simulation of green roof based on the mathematical model is a significant method of quantifying the runoff regulating capacity of green roof [22].

To reduce the rainfall flood disasters, over 40 countries have carried out researches and practices of rainwater control and utilization, proposed stormwater management technologies and methods, and simulation technology is one of the most important stormwater utilization and management methods. Some of these models are SWMM and SUSTAIN based on LID in the USA, Info Works CS model based on SuDs in a Great Britain, and DS based oh Spongy City Construction in China [23,24]

Modelling the reduction in runoff on stormwater roofs in Brussels, Belgium through green roof retrofit showed that typical traditional non-green roofs experienced between $62 \%$ to $91 \%$ runoff (a median of 85\%). On the other hand, intensive green roofs experienced run-off between $15 \%$ and $35 \%$ (median 25\%) and extensive green roofs experienced run-off of 19\% - 73\% (median $55 \%)[11]$. 
Other studies also showed almost the similar results in runoff retention performance from the other green roofs. According to the Stovin., et al. who planted the small green roof in Sheffield (UK), the results have shown the runoff retention approximately to 50-59\%. Similarly, Kohler., et al. studied the green roof ( 5 and $12 \mathrm{~cm}$ depth) in Germany and his results indicated that resulting from a large amount of evaporation from the green roof, rainfall runoff can reduce up to $60-80 \%$.

Also, some experience regarding green roof efficiency in different circumstances are presented in this chapter. An analysis of green roof current research demonstrates substantial evidence suggesting that green roof design factors such as media depth, roof slope, roof age, plant selection, and study period all significantly affect stormwater retention performance $[1,4]$.

The characteristics of soil substrates, its depth and especially green roof vegetation are the most prominent factor in the runoff volume retention. Runoff retention results of the green roofs also depend on the age of the green roof. Previous studies showed that the older green roofs can retain more rainfall runoff as compared to the new green roof. An example of this can be found from Getter., et al. (2007) experiments, whose results indicated that over a 5-year period, the organic matter content of the green roof's soil substrate was doubled. Therefore, the pore spaces were doubled and it increased the water holding capacity of the green roof.

One important factor is the impact that green roof location and climate region has on the retention performance [11]. Capacity of green roof is dependent on the season; hence, there is a great deal of runoff variation due to season changes (Stahre, 2008). Significantly the runoff was much lower in warmer summer months, some $80 \%$ winter runoff versus $52 \%$ summer runoff for green roofs compared to $86 \%$ winter and $70 \%$ summer runoff for gravel roofs. This is largely because during the wetter winter periods roofs become saturated and are unable to absorb much additional rainfall.

\section{Conclusions}

Green roof application proved to be a sustainable approach to mitigating the impact of urbanization and climate changes in developed areas. Green roofs offer an option for decentralized management of rainwater falling on building roofs. It helps to reduce the volume of runoff, delays and reduces peak stormwater runoff flow rates and can reduce pollutants carried to water bodies through the runoff.

Using an appropriate design which integrates different technical options can prove useful to increase the efficiency of green roofs in different circumstances (climate region, season etc.).
In conclusion there is a need to increase the level of awareness, knowledge and understanding of green roof retrofit of practitioners involved in the maintenance and refurbishment of buildings. There is a need to engage with academics and practitioners from other disciplines such as entomologists and horticulturalists to arrive at optimum design solutions for green roof retrofits. Also, the professional bodies have a role to play with the provision of best practice guidelines and notes for members so that they are able to learn about the technical issues and factors to take into account in decision making.

A well-established green roof industry in Germany, good experience in Sweden and relatively less experience and lack of market competition the other regions offers an opportunity for transfer of technology and knowledge between the regions. To increase the efficiency of stormwater management measures, Villarreal (2007) suggests that green roofs should be implemented in combination with other best practices in stormwater management.

\section{Bibliography}

1. J Trincheria and A Yemaneh. "New Knowledge on Urban Stormwater Management". Final Report of the Baltic Flows project, Hamburg University of Applied Sciences and Technical University of Hamburg-Harburg (2016).

2. M Shafique., et al. "Green Roof for Stormwater Management in a Highly Urbanized Area: The Case of Seoul, Korea". Sustainability 10.3 (2018): 584.

3. L Bonzanigo and G Sinnona. "Present Challenges for Future Water Sustainable Cities: a case study from Italy". Drink Water Engineering and Science7 (2014): 35-40.

4. S Sharma. "Effects of Urbanization on Water Resources - Facts and Figures". International Journal of Scientific \& Engineering Research 8.4 (2017): 433-459.

5. L Jotte G., et al. "Review of storm water management practices - Raport". SINTEF Building and Infrastructure, Trondheim, Norway (2017).

6. P K Maeda., et al. "Linking stormwater Best Management Practices to social factors in two suburban watersheds". PIoS ONE 13.8 (2018): e0202638.

7. Askarizadeh A., et.al. "From Rain Tanks to Catchments: Use of Low-Impact Development To Address Hydrologic Symptoms of the Urban Stream Syndrome". Environmental Science and Technology 49.19 (2015): 11264-11280. 
8. Maeda PK. "Knowledge, attitudes, and implementation of BMPs and mosquito management across a socioeconomic gradient”. M.S. Thesis: University of Maryland. (2017).

9. Wang Y. "A diagnostic decision support system for selecting best management practices in urban/suburban watersheds". Ph.D. Thesis: University of Maryland (2015).

10. S Wilkinson., et al "Technical considerations in green roof retrofit for stormwater attenuation in the Central Business District". Structural Survey 33.1 (2015): 33 - 51.

11. Andrew W Sims. "Stormwater Management Performance of Green Roofs". (The University of Western Ontario), Thesis and Dissertation Repository 121 (2015).

12. Landscape Development and Landscaping Research Society e.V. (FLL), - Green Roof Guidelines - Guidelines for the Planing, construction and maintenance of green roofs, $6^{\text {th }}$ edition, 15 Bonn, Germany, 2018.

13. C. Hinman. "Rain Garden Handbook for Western Washington, A Guide for Design, Mainte". ance, and Installation, Washington State University, Department of Ecology State of Washington (2013).

14. S Echols and E Pennypacker. "Artful Rainwater Design : Creative Ways to Manage Stormwater". Washington, DC: Island Press (2015).

15. U Berardi., et al. "State-of-the-art analysis of the environmental benefits of green roofs". Applied Energy 115 (2014): 411-428.

16. US EPA. "Protecting water quality from urban runoff" (2003).

17. US EPA. "Nutrient Indicators Dataset” (2015).

18. K H Kok., et al. "Evaluation of green roof as green technology for urban stormwater quantity and quality controls". IOP Conference Series: Earth and Environmental Science $4^{\text {th }}$ International Conference on Energy and Environment 16.1 (2013).

19. D Zhang., et al. "Conventional and decentralized urban stormwater management: A comparison through case studies of Singapore and Berlin Germany". Urban Water Journal 14.2 (2017): 113-124.

20. Greener Cities in Europe - European Federation of Green Roofs and Walls (EFB), White Paper, 12 (2015).
21. L Hoang and RA Fenner. "System interactions of stormwater management using sustainable urban drainage systems and green infrastructure". Urban Water Journal13.7 (2016): 739758.

22. L Li Xiaoqing., "Application of Green Roof in Relieving Urban Waterlogging: A Review". Journal of Landscape Research 9.6 (2017): 74-76.

23. Whitaker Center for Science and the Arts. The Bay Watershed (2017).

24. Chesapeake Bay Program. Stormwater Runoff | Chesapeake Bay Program.

Volume 3 Issue 7 July 2019

(C) All rights are reserved by Suvada Jusić., et al. 